\title{
Assessment of the Risk of Violence in Portuguese Psychiatric Settings Using the Brøset Violence Checklist
}

\author{
Maria Isabel Marquesa, Aida Bessab, Licínia Santos ${ }^{b}$, Sara Carvalhoc, Goreti Neves ${ }^{b}$
}

\begin{abstract}
The risk of violence in psychiatric settings implies the assessment of dynamic predictors to adjust nursing interventions. So as to identify the pattern of aggressive behaviors, assess the dynamic predictors of violence in hospitalized patients, and analyze the predictive qualities of the Brøset Violence Checklist (BVC), an exploratory/descriptive study was conducted in psychiatric wards in Coimbra, Portugal. The instruments used were: the staff observation aggression scale-revised (SOAS-R), visual analogue scale (VAS), and the BVC. For the period of a month, 64 patients with a mean age of 29 years, unemployed, and with psychotic disorders were observed. In this group, 13 people displayed 15 aggressive behaviors of moderate severity, which had consequences for nurses; they were triggered by the denial of something through verbal aggression and controlled by non-restrictive measures. The most common predictors of violence were irritability and boisterousness. It was also concluded that the BVC shows good predictive characteristics (sensitivity and specificity) of violence, thus, it may be considered as a useful and effective instrument to assess the risk of violence and, consequently, to adjust nursing interventions to prevent this phenomenon.
\end{abstract}

\section{Keywords}

Risk assessment, violence, patients, psychiatry

In short-stay acute psychiatric units, patients are often in a crisis and at risk of displaying aggressive behaviors (Marques, Mendes, and De Sousa 2010). Although most of them end up not displaying those behaviors, nurses play a key role in the prevention and control of these type of behaviors (Björkdahl, Olsson, and Palmstierna 2006), given the relational nature of their profession and the implications of such behaviors on the organization of psychiatric units (Jansen, Middel, and Dassen 2005). Controlling those behaviors is a challenge for the health care teams, because they compromise the therapeutic environment, while interfering with the other patients' safety, demoralizing the staff and sometimes causing severe damages. Therefore, it becomes important to assess the risk of this type of behavior, so as to act properly and facilitate prevention.

Estimating or predicting the risk of violence means to assess the likelihood of a patient's displaying aggressive behaviors, taking into account

\footnotetext{
aNursing School of Coimbra, Portugal

bUniversity Hospital of Coimbra, Portugal

${ }^{c}$ Community Health Center in Figueira da Foz, Portugal

Correspondent Author:

Maria Isabel Marques, Rua da Constituição, no 53 , lote 2, R/C-Fala, 3045-047, Coimbra, Portugal

E-mail: imarques@esenfc.pt
} 
the static and dynamic risk factors (predictors) (Pueyo and Illescas 2007). According to Bullard (2001), static predictors include the patient's previous and recent historical factors of violence/aggression, i.e., those that cannot be changed. Dynamic predictors are warning signs that suggest the occurrence of those behaviors and may include some psychopathological manifestations (Bullard 2001).

Currently, there are several instruments to predict violent behaviors. Among them, the most commonly used are those that enable to assess the risk of violence in prisoners and forensic psychiatric patients in order to plan for their probation arrangements and hospital discharge into the community. However, those instruments seem not to be regularly used in other psychiatric contexts (Pueyo and Illescas 2007). Still, according to Abdalla-Filho (2004), the evidence points to the importance of a balanced assessment between clinical examination and risk factors, using instruments that enable their measurement. However, there are few tools specifically developed to assess the risk of violence in inpatient units (Daffern 2007).

Furthermore, Almvik and Woods (2003) developed the Brøset Violence Checklist (BVC), which is a diagnostic tool used by nursing professionals to assess the short-term risk of violence within the first 24 hours after the patient's admission.

In view of the above, and given that we are unaware of the use of this tool in short-stay psychiatric units in Portugal and the fact that its psychometric characteristics need to be assessed to be effectively used, this study was carried out with the following objectives: to assess the risk of violence in inpatients and characterize the observed aggressive behaviors aiming at an early intervention to prevent them.

\section{RESEARCH QUESTIONS}

The following research questions were formulated in this study to respond to the problem identified:

(1) What is the pattern of aggressive behaviors in patients admitted to the short-stay psychiatric units of the former HUC (Hospitais da Universidade de Coimbra, Coimbra University Hospital) and CHPC (Coimbra Psychiatric Hospital Centre)?

(2) What are the most common dynamic predictors of violence among patients admitted to the short-stay psychiatric units of the former HUC and CHPC?

(3) What are the sensitivity and specificity of the BVC (Almvik and Woods 2003) to predict violent behaviors?

\section{AIMS}

The following objectives were set out:

(1) To characterize the pattern of aggressive behavior in patients admitted to the short-stay psychiatric units of two hospitals in Coimbra, central region of Portugal;

(2) To identify the most common dynamic predictors of violence among patients admitted to the selected short-stay psychiatric units;

(3) To assess the sensitivity and specificity of the BVC to predict violent behaviors.

\section{METHOD}

In order to fulfil these objectives, an exploratory/descriptive study was carried out in four short-stay psychiatric units of two hospitals located in Coimbra, central region of Portugal, two female units and two male units. During one month, 135 patients were admitted to those units.

\section{Participants}

As can be seen in Table 1, the sample included 64 ( $\mathrm{n}=$ 64) of those patients, who were predominantly female (56.3\%); with a mean age of 44 years; had completed or had less than a 9th-grade education (73.4\%); were unemployed (68.8\%); had psychotic and 
schizophrenic disorders (43.8\%); were admitted through the emergency department (64.1\%); were admitted on a voluntary basis (79.7\%); and had already been previously admitted (73.4\%).

\section{Measures}

The following instruments were used: (1) staff observation aggression scale-revised (SOAS-R) (Nijman et al. 1999; Marques et al. 2010); (2) Visual Analogue Scale (VAS); and (3) BVC (Almvik and Woods 2003).

The SOAS-R. The SOAS-R (Nijman et al. 1999), version of Marques et al. (2010), is an instrument used to systemize the records of aggressive incidents, thus allowing for a characterization and quantification of the phenomena. The SOAS- $R$ includes five components: provocation; means used by patient; target(s) of aggression; consequence(s) for victim(s), and measure(s) to stop aggression. Its total scores range from 0 to 22 points.

The VAS. The VAS is an analogue scale used by health care professionals to measure the severity of violent behaviors. The behaviors are rated on a $0-100$ $\mathrm{mm}$ scale ranging from "not severe at all" to "extremely severe". The professional who observes the incident rates his/her perception of the severity of the incident.

The BVC. The BVC of Almvik and Woods (2003) includes six items: confusion, irritability, boisterousness, verbal threats, physical threats, and attacks on objects. Absence of behavior gives a score of 0 . Presence of behavior gives a score of 1 , obtaining a maximum score of 6 . According to the authors, the scoring should be interpreted as follows: If the total score is 0 , the risk of violence is small; if it is 1 or 2 , the risk of violence is moderate and preventive measures should be taken; if it is higher than 2, the risk of violence is very high and preventive measures should be taken immediately, and a plan should be developed to manage the potential violence.

\section{Procedures}

All ethical-legal procedures were respected and subject to the approval of the Ethics Committee.

Although the selected units have multidisciplinary teams, the professionals selected to participate in the study were nurses, as the BVC is a specific nursing tool to assess the risk of violence based on dynamic predictors. Thus, the nurses assessed the risk of violence of the patients hospitalized in their units within the first 24 hours after admission.

Following the recommendations of the BVC authors, in this study, the researchers requested the nurses to assess the patient with the 24-hour period (after admission) in the first two hours of each shift: night, morning, and afternoon. The contribution of these nurses was also essential to assess the risk of violence and monitor the aggressive behaviors, as they were with the patients throughout the whole day and have professional training and expertise to intervene in case of these type of behaviors. Therefore, it was possible to monitor these behaviors through the nurses' clinical observation of inpatients during the 24-hour period and record them in the violent behavior observation scale- - the SOAS-R.

\section{DATA ANALYSIS}

Data were analyzed using the SPSS (Statistical Package for Social Sciences), Version 19.0. Statistical measures were used, namely absolute and relative frequencies, means, and the Spearman's correlation coefficient.

The characteristics of the BVC were assessed based on the guidelines recommended for assessment of criterion validity taking into account its sensitivity and specificity (Almvik, Woods, and Rasmussen 2000). Sensitivity is the number of correctly identified positive cases, while specificity is the number of correctly identified negative cases. Therefore, it was necessary to identify the positive predictive value 
Table 1. Sample Characterization

\begin{tabular}{llll}
\hline & Characterization & $\mathrm{n}=64$ & Percent (\%) \\
\hline \multirow{2}{*}{ Gender } & Male & 28 & 43.8 \\
& Female & 36 & 56.3 \\
\hline Age & Max.: 13 years; Min.: 77 years; Mean: 44 years & \\
\hline \multirow{4}{*}{ Marital status } & & $\mathrm{n}=64$ & Percent (\%) \\
& Married + cohabitation & 30 & 46.9 \\
\hline \multirow{2}{*}{ Education } & Widowed + divorced & 11 & 17.2 \\
\hline \multirow{2}{*}{ Profession } & Single & 35.9 \\
\hline \multirow{2}{*}{ Admission } & $\leq 9$ th-grade & 23 & 73.4 \\
& $>9$ th-grade & 47 & 26.6 \\
\hline \multirow{2}{*}{ Mode of admission } & Employed & 17 & 31.3 \\
& Non-employed & Compulsive & 68.8 \\
\hline \multirow{2}{*}{ Previous admissions } & Volunteer & 40 & 20.3 \\
& Consultation & 13 & 79.7 \\
\hline & Emergency & 51 & 18.8 \\
& Legal & 12 & 64.1 \\
& Psychotic + schizophrenic & 41 & 17.2 \\
\hline
\end{tabular}

(PPV), which indicates the probability of the identified cases being truly positive, and the negative predictive value (NPV), which indicates the probability of the identified cases being truly negative, as well as the incorrect classification rate, i.e., the number of individuals incorrectly identified as positive or negative.

In line with the study objectives, data treatment and analysis focused on the study sample ( $\mathrm{n}=64$ patients), the number of patients who displayed aggressive behaviors ( $\mathrm{n}=13$ patients), and the number of aggressive behaviors observed ( $\mathrm{n}=15$ behaviors).

\section{RESULTS}

The presentation of results includes the results related to the:
(1) Characterization of the pattern of aggressive behaviors in patients admitted to the short-stay psychiatric units of two hospitals in Coimbra, central region of Portugal;

(2) Violence risk assessment and identification of the most common dynamic predictors among patients admitted to selected short-stay psychiatric units using the BVC (Almvik and Woods 2003);

(3) Assessment of the sensitivity and specificity of the BVC (Almvik and Woods 2003) to predict violent behaviors.

\section{The Pattern of Aggressive Behaviors of in Patients Admitted to Short-Stay Psychiatric Units Includes}

(1) The identification of the socio-demographic and clinical characteristics of the 13 patients who 
displayed aggressive behaviors, which were recorded by nurses over the course of a month;

(2) The characterization of aggressive behaviors according to the classification by (Nijman et al. 1999) regarding their nature and severity, in line with the score assigned to the SOAS-R by the same author;

(3) The classification of the risk of violence according to the BVC and also the assessment of its sensitivity and specificity.

Socio-demographic and clinical characteristics of patients who displayed aggressive behaviors. Of the 64 patients participating in the study, 13 patients displayed aggressive behaviors. Their characteristics were the following: Most were male (53.8\%), with a mean age of 29 years, their marital status was married + cohabitation and single (46.2\%), they had completed or had less than a 9th-grade education (53.8\%); were unemployed (76.9\%), had psychotic and schizophrenic disorders (76.9\%), were admitted through the Emergency Department and Legal System (46.2\%), were admitted on a voluntary basis (53.8\%); and had already been previously admitted (73.4\%).

Characteristics of the aggressive behaviors recorded. In relation to the characterization of aggressive behaviors, the authors considered the 15 behaviors displayed by the 13 previously characterized patients. The components inherent to the nature, severity, and identification of the context of occurrence were identified.

Taking into account the SOAS-R components (see Table 2), the most significant results (highest frequencies) showed that the aggressive behaviors were triggered by a denial of something (46.7\%), used verbal aggression (93.3\%), targeted mostly nurses (66.7\%), had consequences (80\%) especially for people, which resulted specifically in feelings of threat (26.7\%) and needs for medical treatment (13.3\%), and were controlled through non-restrictive measures, specifically talking with the patient (22.8\%) and showing calm (21.1\%).

As for the severity of the aggressive behaviors, the
SOAS-R (see Table 3) allowed to verify that many of them were classified as of moderate severity (46.7\%).

\section{Risk of Violence, Most Common Dynamic Predictors Among Patients Admitted to the Short-Stay Psychiatric Units and Characteristics of the $B V C$}

The risk of violence was classified by: (1) characterizing the risk of the 13 patients who ended up displaying aggressive behaviors, according to the classification presented by Almvik and Woods (2003), with different scores being assigned to the various items of the BVC, whose classification included the following levels: high risk (score $>2$ ), moderate risk (score $=1$ and 2 ), and low risk (score $=0$ ); and (2) identifying the most common dynamic predictors.

As can be seen in Table 4, 10 of the 13 patients who displayed aggressive behaviors showed high risk levels (76.9\%) according to the abovementioned classification.

In order to identify the most common predictors (confusion, irritability, anger, verbal threat, threat of physical aggression, and threat against objects), the authors chose to present the results of both the total sample ( $n=64$ patients) and the specific sample referring to the number of patients who displayed aggressive behaviors ( $\mathrm{n}=13$ patients).

As can be seen in the following table (see Table 5), the most common dynamic predictors in both samples ( $\mathrm{n}$ and $\mathrm{n}_{1}$ ) were irritability, boisterousness, and verbal threats.

\section{Assessment of the Criteria of Sensitivity and Specificity of the BVC}

As previously described in the chapter on methodology, the researchers chose to follow the guidelines by the authors of the BVC to assess the tool's sensitivity and specificity.

In that sense, the assessment was based on the identification of the levels of risk of violence according to the author's classification, taking into 
Table 2. Characterization of the Aggressive Behaviors According to Their Nature

\begin{tabular}{|c|c|c|c|}
\hline Components & Characterization & $\mathrm{n}=15$ & $\begin{array}{l}\text { Percent } \\
(\%)\end{array}$ \\
\hline \multirow{5}{*}{ 1. Provocation } & Unidentified & 3 & 20 \\
\hline & Other patients & 2 & 13.3 \\
\hline & Help with the satisfaction of basic needs/ADLs (Daily Living Activities) & 1 & 6.7 \\
\hline & Denial of something & 7 & 46.7 \\
\hline & Order to take medication & 2 & 13.3 \\
\hline \multirow{17}{*}{ 2. Means used by patient } & Verbal aggression: & & \\
\hline & Yes & 14 & 93.3 \\
\hline & No & 1 & 6.7 \\
\hline & Parts of the body: & & \\
\hline & None & 5 & 33.3 \\
\hline & Hands & 7 & 46.7 \\
\hline & Feet & 1 & 6.7 \\
\hline & Teeth & 1 & 6.7 \\
\hline & Others & 1 & 6.7 \\
\hline & Ordinary objects (chairs, glass, others) & & \\
\hline & None & 11 & 73.3 \\
\hline & Chairs & 2 & 13.3 \\
\hline & Other & 2 & 13.3 \\
\hline & Dangerous objects (knives, others) & & \\
\hline & None & 14 & 93.33 \\
\hline & Others & 1 & 6.67 \\
\hline & Dangerous methods (strangulation, others) & - & - \\
\hline \multirow{6}{*}{ 3. Target of aggression } & Nothing/Nobody & 2 & 13.3 \\
\hline & Objects & 0 & 0 \\
\hline & The patient himself/herself & 2 & 13.3 \\
\hline & Other patients & 1 & 6.7 \\
\hline & Nurses & 10 & 66.7 \\
\hline & Others & - & - \\
\hline \multirow{12}{*}{$\begin{array}{l}\text { 4. Consequences for the } \\
\text { victim }\end{array}$} & Yes & 12 & 80 \\
\hline & No & 3 & 20 \\
\hline & Objects & & \\
\hline & None & 12 & 80 \\
\hline & Recovered damage & 3 & 20 \\
\hline & Persons & & \\
\hline & None & 3 & 20 \\
\hline & Felt threatened & 4 & 26.7 \\
\hline & Felt pain for less than $10 \mathrm{~min}$. & 2 & 13.3 \\
\hline & Visible (bodily) injuries & 3 & 20 \\
\hline & Need for treatment & 1 & 6.7 \\
\hline & Need for medical treatment & 2 & 13.3 \\
\hline \multirow{7}{*}{$\begin{array}{l}\text { 5. Measures to stop } \\
\text { aggression }\end{array}$} & Talk to the patient & 13 & 22.8 \\
\hline & Show calm & 12 & 21.1 \\
\hline & Peroral medication & 5 & 8.8 \\
\hline & Parenteral medication & 5 & 8.8 \\
\hline & Held with force & 8 & 14 \\
\hline & Isolation & 7 & 12.3 \\
\hline & Physical restraints & 7 & 12.3 \\
\hline
\end{tabular}


Table 3. Severity of the Aggressive Behaviors (SOAS-R)

\begin{tabular}{lll}
\hline & $\mathrm{n}$ & Percent (\%) \\
\hline Slight & 2 & 13.3 \\
Moderate & 7 & 46.7 \\
Severe & 6 & 40.0 \\
Total & 15 & 100 \\
\hline
\end{tabular}

Table 4. Characterization of the Risk of Violence Using the BVC

\begin{tabular}{lll}
\hline & $\mathrm{n}$ & Percent $(\%)$ \\
\hline Low risk & - & - \\
Moderate risk & 3 & 23.1 \\
High risk & 10 & 76.9 \\
Total & 13 & 100.0 \\
\hline
\end{tabular}

Table 5. Characterization of the Frequency of Dynamic Predictors of Violence (BVC)

\begin{tabular}{|c|c|c|c|c|c|c|c|c|}
\hline \multirow{3}{*}{ Predictors of violence } & \multicolumn{4}{|c|}{$\mathrm{n}=64$} & \multicolumn{4}{|c|}{$\mathrm{n}_{1}=13$} \\
\hline & \multicolumn{2}{|c|}{ Absent } & \multicolumn{2}{|c|}{ Present } & \multicolumn{2}{|c|}{ Absent } & \multicolumn{2}{|c|}{ Present } \\
\hline & $\mathrm{n}$ & $\%$ & $\mathrm{n}$ & $\%$ & $\mathrm{n}_{1}$ & $\%$ & $\mathrm{n}_{1}$ & $\%$ \\
\hline Confusion & 60 & 93.8 & 4 & 6.3 & 11 & 84.61 & 2 & 15.38 \\
\hline Irritability & 45 & 70.3 & 19 & 29.7 & 1 & 7.69 & 12 & 92.30 \\
\hline Boisterousness & 45 & 70.3 & 19 & 29.7 & 1 & 7.69 & 12 & 92.30 \\
\hline Verbal threats & 52 & 81.3 & 12 & 18.8 & 2 & 15.38 & 11 & 84.61 \\
\hline Physical threats & 55 & 85.9 & 9 & 14.1 & 4 & 30.77 & 9 & 69.23 \\
\hline Attacks on objects & 58 & 90.6 & 6 & 9.4 & 7 & 53.85 & 6 & 46.15 \\
\hline
\end{tabular}

account the frequency of patients who displayed and those who did not display aggressive behaviors. Thus, recalling what was previously described, Table 6 shows that 13 of the 64 patients studied ended up displaying aggressive behaviors (10 showed high risk levels and three showed moderate risk levels), while 51 did not display aggressive behaviors (43 showed low risk levels and eight showed moderate risk levels).

In order to assess the predictive quality of the BVC, Almvik et al. (2000) used, as a reference, a calculation formula that included the allocation of predictive values to cases (see Table 7):

In view of the above, and in accordance with Almvik et al. (2000), the sensitivity and specificity were calculated taking into account the following aspects:
The sensitivity of the BVC: A score of 2 or more predicts violent events in the next 24-hour period. The formula used was True Positive/(True Positive + False Negative). In this case, the sensitivity of the BVC = $10 /(10+13)$ was .77 (77\%).

The specificity of the BVC: Scores of 0 and 1 mean that the frequency of predicting non-violence is correct. The formula used was True Negative/(True Negative + False Positive). In this case, the specificity of the BVC $=51 /(51+0)$ was 1, i.e., $100 \%$.

Taking into account the previously described characteristics of the BVC, the researchers also aimed at assessing these characteristics considering the severity of the aggressive behaviors recorded according to the SOAS-R classification. Through the Spearman's correlation coefficient, it was only observed that the BVC showed sensitivity $(r=.811)$ 
Table 6. Assessment of the Risk of Violence and Display of Aggressive Behaviors

\begin{tabular}{llllll}
\hline & & \multicolumn{3}{c}{ Risk of violence } \\
\cline { 3 - 6 } & & Low & Moderate & High & $\mathrm{n}$ \\
\hline Aggressive & Present & - & 3 & 10 & 13 \\
behaviors & Absent & 43 & 8 & - & 51 \\
Total & & 43 & 11 & 10 & 64 \\
\hline
\end{tabular}

Table 7. Allocation of Predictive Values in Accordance With Almvik et al. (2000)

\begin{tabular}{llll}
\hline & & \multicolumn{2}{c}{ Aggressive behaviors } \\
\cline { 3 - 3 } & & Present & Absent \\
\hline \multirow{2}{*}{ Risk of violence } & Present & $10(\mathrm{TP})$ & $-(\mathrm{FP})$ \\
& Absent & $3(\mathrm{FN})$ & $51(\mathrm{TN})$ \\
\hline
\end{tabular}

Notes: TP-True Positive; FP-False Positive; FN—False Negative; TN-TrueNegative.

to predict the severity of aggressive behaviors.

\section{DISCUSSION}

Taking into account that the phenomenon of violence in psychiatric settings has been considered both a prevalent (Hamolia 2006; Björkdahl et al. 2006), particularly in acute psychiatric units, and a worrying phenomenon in view of its consequences and complexity, it was considered important to assess the risk of violence among inpatients and characterize the observed aggressive behaviors, with the purpose of intervening early and preventing these behaviors.

In this sense, the results obtained in the present study, inherent to the characterization of the pattern of aggressive behaviors among the patients hospitalized in the selected psychiatric units, especially those that stood out, revealed that 13 of the 64 patients displayed aggressive behaviors whose characteristics are similar to those identified in other studies, namely younger patients (James et al. 1990) and patients with severe psychiatric disorders (Bjørkly 1995; Nijman et al. 1999).

In terms of the characteristics of the 15 aggressive behaviors that were registered, they are also similar to those that have been described in studies conducted in similar contexts. More specifically, as regards the provocation, denial of something (Nijman et al. 1997), the method used for aggression (verbal aggression), (Nijman et al. 1999; Cembrowicz, Ritter, and Wright 2001), the target, the nurses (Kwok et al. 2006; Nijman et al. 2005), the moderate severity as in Marques et al. (2010), the use of non-restrictive measures, which is in line with the most recent international recommendations (Bergk, Einsiedler, and Steinert 2008).

In addition to other measures that have been commonly used, especially to control aggression, the prevention of this phenomenon essentially involves the quality of the structured assessment of the risk of violence to intervene in an appropriate manner (Daffern 2007; Pueyo and Illescas 2007; Monahan 2008).

The assessment of the risk of violence through its static and dynamic predictors is an important intervention for the prevention of violence in psychiatric settings, particularly the assessment of the dynamic predictors in short-term units (Almvik and Woods 2003; Björkdahl et al. 2006; Daffern 2007).

The results obtained in this study showed that the most frequently observed dynamic predictors at the selected units were boisterousness and irritability. 
These results are in line with those found in other similar studies (Almvik et al. 2000; Almvik and Woods 2003; Björkdahl et al. 2006). These manifestations are common in acute cases and refer to secondary emotions sometimes followed by aggressive behaviors (Hamolia 2006). These manifestations may be controlled and prevented as long as there is an adequate investment in a therapeutic environment, as well as in favorable conditions for the patient's well-being (Hamolia 2006).

Based on the results found in relation to the sensitivity (77\%) and specificity (100\%) of the BVC scale, which are comparable to those found in other studies (Almvik et al. 2000; Abderhalden et al. 2006; Björkdahl et al. 2006; Abderalden et al. 2008), it can be concluded that it has a good predictive ability for the risk of violence by means of dynamic predictors in short-term psychiatric units.

In this section, reference should be made to some of the limitations of this study, in particular the small sample size $(n=64)$, as well as the limited period for fieldwork (one month), the lack of instruments to regulate the procedures for assessment of the risk of violence, the lack of systematization of records that enable the control over this phenomenon, the training of professionals in this specific field, among others.

Another limitation relates to the observation of aggressive behaviors, which are often devalued by the professionals themselves, as their attitude toward violence is determined by how they assess the patient's behavior (Jansen et al. 2005). In addition, there is still the idea that violence is an inevitable phenomenon in psychiatric settings, by which the professionals themselves often undervalue or ignore it (Nolan et al. 1999). This may have been another limitation in data collection.

\section{CONCLUSIONS}

This study allowed us to identify the pattern of aggressive behaviors recorded during the course of a month in four short-stay psychiatric units, in the district of Coimbra. It also allowed us to analyze the characteristics of the violence risk assessment scale-BVC. The following results of this study should be highlighted:

(1) Of the 64 patients, 13 displayed a total of 15 aggressive behaviors. As regards these patients' characteristics, the following stood out: They had a mean age of 29 years, were unemployed, and had psychotic and schizophrenic disorders. These patients moderately displayed severe behaviors, which were triggered by the denial of something and expressed through verbal aggression, with consequences especially for nurses. They were controlled through non-restrictive measures. The behaviors shown occurred between midday and 3:00 pm at the ward;

(2) Regarding the predictors of violence, the most observed ones were irritability, anger, and verbal threat;

(3) Finally, the BVC showed good predictive characteristics (sensitivity and specificity) of violence.

Therefore, the BVC proved to be an instrument with predictive qualities, which lead us to conclude that it is useful and effective to accurately assess the predictors of violence, thus enabling to adjust nursing interventions to prevent the phenomenon.

This research study may also provide an opportunity for the professionals working at the units where it was conducted to develop a nursing action protocol to prevent aggressive behaviors.

Finally, in terms of the limitations of this study, the observation of aggressive behaviors was often undervalued by the professionals themselves and a lack of systematization of records that enabled to control the phenomenon was also observed.

\section{Funding}

The Nursing School of Coimbra and the Health Sciences Research Unit: nursing supported the study. 


\section{References}

Abdalla-Filho, E. 2004. "Assessing the Risk of Violence in Forensic Psychiatry.” Clinical Psychiatry Journal 31(6):279-284.

Abderhalden, C., I. Needham, T. Dassen, R. Halfens, H.-J. Haug, and J. Fischer. 2006. "Predicting Inpatient Violence Using an Extended Version of Brøset-Violence-Checklist: Instrument Development and Clinical Application.” BMC Psychiatry 6(17):1-8.

—. 2008. "Structured Risk Assessment and Violence in Acute Psychiatric Wards: Randomised Controlled Trial.” The British Journal of Psychiatry 193(2):44-50.

Almvik, R. and P. Woods. 2003. "Short-Term Risk Prediction: The Brøset Violence Checklist.” Journal of Psychiatric Mental Health Nursing 10(2):236-238.

Almvik, R., P. Woods, and K. Rasmussen. 2000. “The Brøset Violence Checklist (BVC): Sensitivity, Specificity and Inter-Rater Reliability.” Journal of Interpersonal Violence 15(12):1284-1296.

Bergk, J., B. Einsiedler, and T. Steinert. 2008. "Feasibility of Randomized Controlled Trials on Seclusion and Mechanical Restraint.” Clinical Trials 5(4):356-363.

Björkdahl, A., D. Olsson, and T. Palmstierna. 2006. "Nurses' Short-Term Prediction of Violence in Acute Psychiatric Intensive Care." Acta Psychiatrica Scandinavica 113(3):224-229.

Bjørkly, S. 1995. "Prediction of Aggression in Psychiatric Patients, a Review of Prospective Prediction Studies.” Clinical Psychology Review 15(6):475-502.

Bullard, H. 2001. "Mental Disorder and Violence.” Pp. 44-62 in Violence in Healthcare: Understanding, Preventing and Surviving Violence: A Practical Guide for Health Professionals, 2nd ed., edited by J. Shepherd. New York: Oxford University Press.

Cembrowicz, S., S. Ritter, and S. Wright. 2001. "Attacks on Doctors and Nurses." Pp. 118-154 in Violence in Healthcare: Understanding, Preventing and Surviving Violence: A Practical Guide for Health Professionals, 2nd ed., edited by J. Shepherd. New York: Oxford University Press.

Daffern, M. 2007. "The Predictive Validity and Practical Utility of Structured Schemes Used to Assess Risk for Aggression in Psychiatric Inpatient Settings.” Aggression and Violent Behavior 12(1):116-130.

Hamolia, C. C. 2006. "Preventing and Managing Aggressive Behavior.” Pp. 654-677 in Principles and Practice of Psychiatc Nursing, 8th ed., edited by G. W. Stuart and M. T. Laraia. Porto Alegre: Art Med.

James, D., N. Finiberg, A. Snah, and R. Priest. 1990. “An Increase in Violence on an Acute Psychiatric Award: A
Study of Associated Factors.” The British Journal of Psychiatry 156(1):846-852.

Jansen, G. J., B. Middel, and T. W. N. Dassen. 2005. “An International Comparative Study on the Reliability and Validity of the Attitudes Toward Aggression Scale.” International Journal of Nursing Studies 42(4):467-477.

Kwok, R. P., Y. K. Law, K. E. Li KE, Y. C. Ng, M. H. Cheung, V. K. P. Fung, ... W. C. Leung. 2006. "Prevalence of Workplace Violence Against Nurses in Hong Kong." Hong Kong Medicine Journal 12(1):6-9.

Marques, M. I. D., A. C. Mendes, and L. De Sousa. 2010. "Aggressive Behaviours of Inpatients in Psychiatric Context.” Pp. 121-146 in Advice on Health: Integrative Perspectives, edited by E. J. Ribeiro dos Santos, J. A. Ferreira, P. Santo, J. Leitão, R. David, C. Figueiredo, C. Seixas, and J. Almeida. Viseu: Psicosoma.

Monahan, J. 2008. "Structured Risk Assessment of Violence.” Pp. 17-33 in Textbook of Violence Assessment and Management, edited by R. I. Simon and K. Tardiff. Washington, D.C.: American Psychiatric Publishing.

Nijman, H., L. Bowers, N. Oud, and G. Jansen. 2005. "Psychiatric Nurses' Experiences With Inpatient Aggression.” Aggressive Behaviour 31(3):217-227.

Nijman, H., P. Muris, H. L. G. J. Merckelbach, T. Palmstierna, B. V. Wistedt, A. V. Rixtel, and W. Allertz. 1999. "The Staff Observation Aggression Scale-Revised (SOAS-R).” Aggressive Behaviour 25(3):197-209.

Nijman, H., W. F. F. Alertz, H. L. G. J. Merckelbach, J. L. M. G. À Campo, and D. P. Ravelli. 1997. "Aggressive Behavior on an Acute Psychiatric Admission Ward.” The European Journal of Psychiatry 11(2):106-114.

Nolan, P., J. Dallender, J. Soares, S. Thomsen, and B. Arnetz. 1999. "Violence in Mental Health Care: The Experiences of Mental Health Nurses and Psychiatrists." Journal of Advanced Nursing 30(4):934-941.

Pueyo, A. A. and S. R. Illescas. 2007. "Prediction of Violence: Between Hazart and Risk Assessement of Violence." Psychologist Papers 28:157-173.

\section{Bios}

Maria Isabel Marques, Ph.D. in mental health, professor, RN, mental health nurse, Nursing School of Coimbra, Portugal; research fields: prevention of violence in psychiatric context, mental health promotion in community based in complementary interventions (animal assisted interventions - dog, music therapy, and laughter therapy).

Aida Bessa, MA candidate in mental health psychiatric nursing, RN, mental health nurse in psychiatric acute units, 
University Hospital of Coimbra, Portugal; research field: prevention of violence in psychiatric context.

Licínia Santos, BA, RN in mental, nurse in dermatology unite, University Hospital of Coimbra, Portugal; research field: prevention of violence in psychiatric context.

Sara Carvalho, BA, RN, mental health nurse in primary care,
Community Health Center in Figueira da Foz, Portugal; research field: prevention of violence in psychiatric context.

Goreti Neves, BA, RN, mental health nurse in psychiatric acute units, head nurse in University Hospital of Coimbra, Portugal; research field: prevention of violence in psychiatric context. 